\title{
Correction to: Photocatalytic degradation of volatile organic compounds using nanocomposite of P-type and N-type transition metal semiconductors
}

\section{Dagmawi Mulugeta Degefu' ${ }^{1}$ Zaiyi Liao ${ }^{1}$}

Published online: 2 July 2021

(c) Springer Science+Business Media, LLC, part of Springer Nature 2021

Correction to: Journal of Sol-Gel Science and Technology (2021) 98:605-614

https://doi.org/10.1007/s10971-021-05532-y

The authors would like to correct the errors in the publication of the original article. The corrected details are given below.

(a) The graphical abstract should be replaced with the following version.

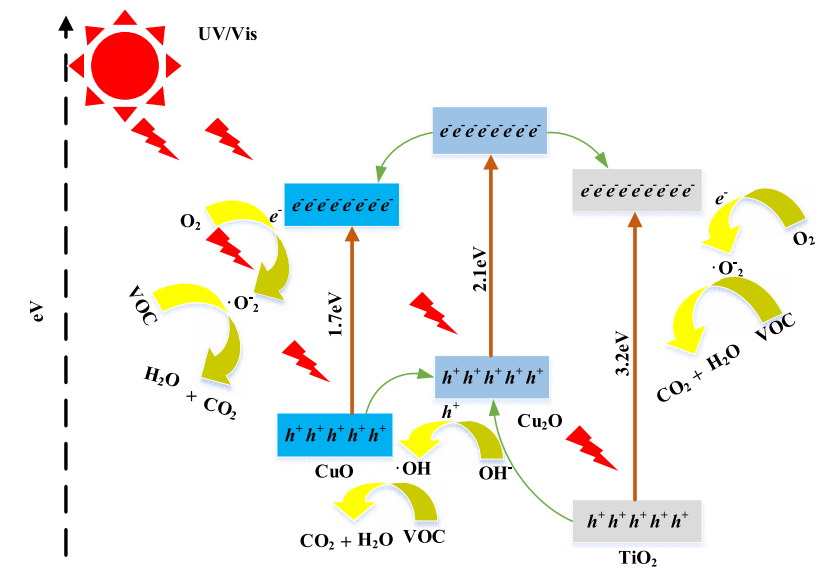

Dagmawi Mulugeta Degefu

dagmawi.degefu@ryerson.ca

1 Faculty of Engineering and Architectural Science, Ryerson

University, P.O. Box M5B 2K3, Toronto, ON, Canada (b) The Fig. 8 should be replaced with the following version.

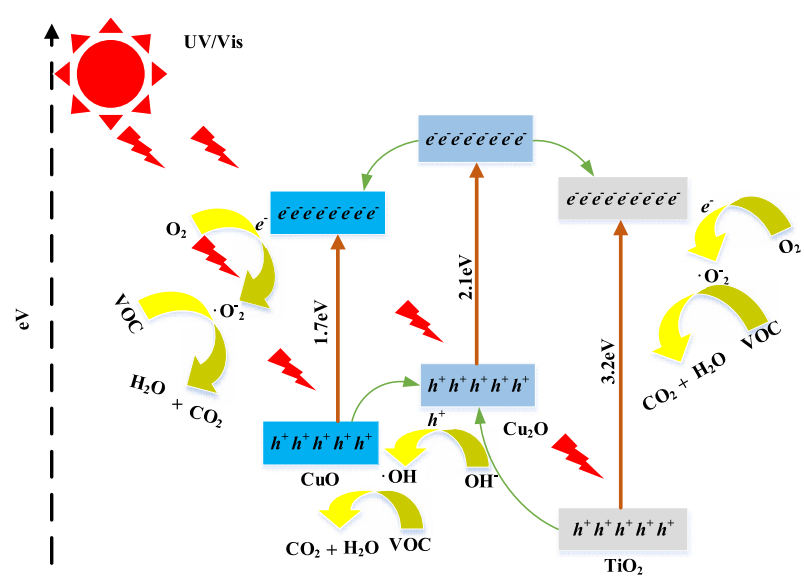

Fig. 8 Mechanism of photocatalysis by semiconductor coupled titanium oxide under UV-Vis light 


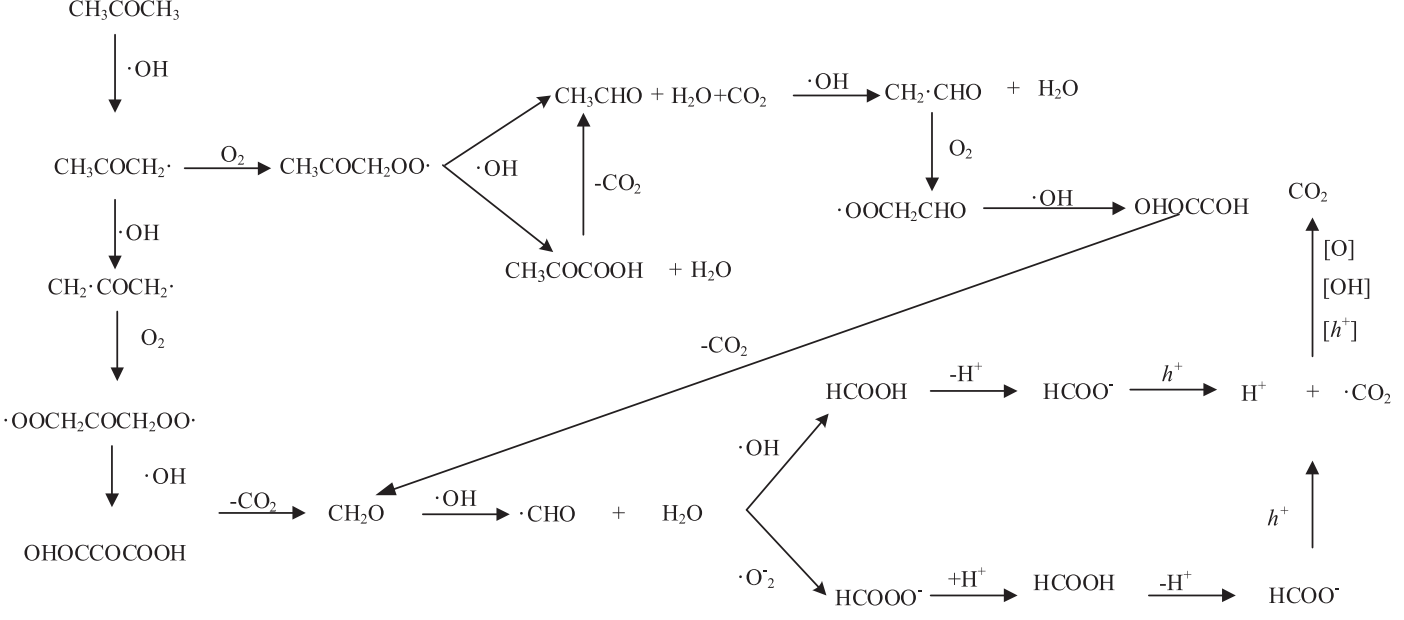

Fig. 9 Redox reaction mechanism of photocatalytic degradation of acetone by semiconductor coupled titanium oxide under UV-Vis lights

(c) The Fig. 9 should be replaced with the following version.

(d) The equations in section 3.4 should be modified follows.

Nanocomposite $+\mathrm{UV} / \mathrm{Vis} \rightarrow e_{C B}^{-}+h_{V B}^{+}$

\section{Nanocomposite $+h_{V B}^{+} \rightarrow \cdot \mathrm{OH}+\mathrm{H}^{+}$}

$\mathrm{O}_{2}+e_{C B}^{-} \rightarrow \cdot \mathrm{O}_{2}^{-}$ 